\title{
Improved Pyrolysis Model of Polymer Materials under Windy Conditions
}

\author{
Lizhong Yang ${ }^{1}$, Dimeng Lai ${ }^{1}$, Yuan Zheng ${ }^{1}$ and Fei Peng ${ }^{1, a}$ \\ ${ }^{1}$ State Key Laboratory of Fire Science, University of Science and Technology of China, Hefei, Anhui province, China
}

\begin{abstract}
The polymer materials are widely used in various occasions, of which polymethyl methacrylate(PMMA) is used in architectural transparent roofs, telephone booths, stairs, and their fire risk is getting more and more attention. The ignition conditions (critical surface temperatures and critical mass flow rates) of polymer materials have extensively researched, but their internal heat transfer studies have been relatively rare, especially in wind environments. Considering that internal heat transfer research is important for the heat transfer of multi-layer materials, the study of heat transfer inside materials is also worthy of attention.

In this work, we found that in-depth absorption theory is more suitable for solid pyrolysis models under wind conditions. An absorption coefficient depends with temperature are assumed, and it fits better than the constant absorption coefficient. In addition, this work made some improvements to the ignition model by employing the theory of in-depth absorption.
\end{abstract}

\section{Introduction}

Polymers have found many applications in construction, such as polymethyl methacrylate commonly used in the transparent roof of buildings, but their fire hazard is worrying. In the building facade and roof fire accidents, air flow velocity plays a vitally important role in the ignition and spread of conflagrations. The forced convection of air flow promotes the thermal plume to take away heat and produces a direct cooling effect on the surface of combustibles. It may affect the ignition mechanism but few relevant articles can be found.

Quintiere [1], Yang [2,3] and Tsai [4] studied the pyrolysis of different types of solid combustibles under various radiant heat fluxes and obtained the relationship between ignition time and radiant heat flux. Hallman et al. [5] found that ignition delay time is strongly influenced by surface absorption. Recently, Lautenberger et al. [6] proposed a generalized pyrolysis model for combustible solids, where the in-depth absorption model was used. Gong et al. [7] established a new model which combines in-depth absorption and surface absorption. For absorption coefficient, G. Linteris et al. [8] obtained the in-depth absorption coefficients of PMMA under different external heat fluxes and averaged them to 1870 .

However, these pyrolysis models for combustible solids were used under no-wind conditions. And the internal temperature distribution of the materials also deserves attention, because of the materials used in combination practically. This work simulates the fire environment under windy conditions using a radiation source and a fan and measures the internal temperature of PMMA in this environment. The goal of this work is to

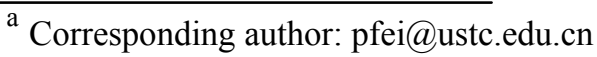

improve solid pyrolysis model under windy conditions by using absorption theories.

\section{Experimental methodology}

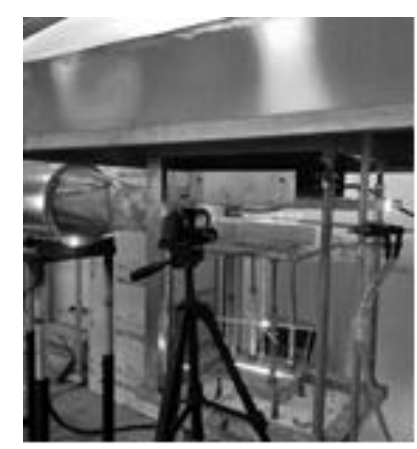

Figure 1. Experimental apparatus.

Figure 1 shows the FFIT (Forced Flow Ignition Test) setup, which consists of a small-scale wind tunnel, a radiation source platform, and support components. The total length of the wind tunnel is 1.3 meters, and the length of inlet section, reducing coupling section, outlet section is $65,25,40$ centimetres respectively. The square source platform (side length $30 \mathrm{~cm}$ ) provides approximately uniform radiation to the sample surface and the incident heat flux is perpendicular to the sample. The distance between the radiation source and the upper surface of the sample is $10 \mathrm{~cm}$.

PMMA is selected as the test sample in the experiments, where the heated surface is $50 \mathrm{~mm} \times 50 \mathrm{~mm}$ and the thickness is $20 \mathrm{~mm}$. The other sides of the 
samples are wrapped in Ceramic fibber, except for the upper surface exposed to radiation. Sample internal temperatures are measured with by a K-type thermocouple placed at the center of the test sample which penetrate from the downstream side of the sample. The thermocouples placed at the distances of 4.5, 10.5, and $16.5 \mathrm{~mm}$ from the exposed surface were used to record internal temperatures. Tests are conducted with radiant fluxes at the sample surface ranging from 19.31 to $35.47 \mathrm{~kW} / \mathrm{m}^{2}$, with the air velocities ranging from 0.5 to $1.43 \mathrm{~m} / \mathrm{s}$. Sample internal temperatures were recorded until sample ignites. However, if ignition did not occur in 15 minutes, it will be judged that the sample cannot ignite under the condition, if the sample doesn't ignite in 15 min. In order to ensure the reliability of the experimental data, the experiments were carried out more than 3 times.

\section{Theoretical analysis}

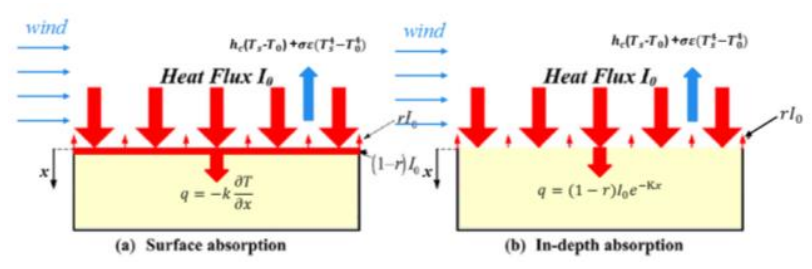

Figure 2. Schematic of heat transfer in PMMA exposed constant radiation in airflow environment.

The control equations for surface absorption and in-depth absorption are equation (1),(2) respectively. Figure 2 is a schematic diagram of two assumptions. The surface absorption assumed that the heat flux is totally absorbed by exposed surface. But for in-depth absorption, incident heat flux is absorbed through the material gradually and it attenuates exponentially. The absorption capability is characterized by an in-depth absorption coefficient which quantifies the absorption of thermal radiation per unit path length within the medium.

$$
\begin{gathered}
\frac{\partial T_{s}}{\partial t}=\alpha \frac{\partial^{2} T_{s}}{\partial x^{2}} \\
\rho_{s} C_{s} \frac{\partial T_{s}}{\partial t}=\frac{\partial}{\partial x}\left(k \frac{\partial T_{s}}{\partial x}\right)+\dot{q}_{e x t}^{\prime \prime} \kappa e^{-\kappa x}
\end{gathered}
$$

In these equations, $\mathrm{a}$ is thermal diffusion coefficient, $\rho_{\mathrm{s}}$ is current solid density, $\mathrm{C}_{\mathrm{s}}$ is specific heat of solid, $T_{\mathrm{s}}$ is solid temperature, $\mathrm{t}$ is time, $\mathrm{k}_{\mathrm{s}}$ is thermal conductivity of solid, $\mathrm{q}_{\mathrm{ext}}$ is the incident heat flux, $\mathrm{k}$ is the in-depth absorption coefficient, $\mathrm{x}$ is the spatial variable. Some reasonable assumptions were used in the process of building a pyrolysis model:

1) Ignore the slight deformation and expansion of the sample during the pyrolysis process;

2) The surface drop due to the decrease in mass must be considered, and it is assumed that the attenuation of the surface occurs only at the outermost layer;

3) The sample is insulated around the mass and the mass is only transmitted in the thickness direction;
4) The internal pyrolysis gas inside the material is precipitated instantaneously;

In order to study the effects of two heat flux absorption assumptions and to facilitate programming, Gong [7] adjusted the internal heat transfer control equation of the polymer to:

$$
\begin{aligned}
& \rho C_{p} \frac{\partial T_{S}}{\partial t}=\frac{\partial}{\partial x}\left(k \frac{\partial T_{S}}{\partial x}\right)+(1-r-\tau) \dot{q}_{\text {ext }}{ }^{\prime} \kappa e^{-\kappa x} \\
& \quad+\rho S_{v}\left[\Delta H_{v}+\left(T_{S}-T_{0}\right)\left(C_{P}-C_{g}\right)\right]-\dot{m}{ }^{\prime} C_{g} \frac{\partial T_{S}}{\partial x}
\end{aligned}
$$

where $\tau=0$ means in-depth absorption assumption, $\tau=1$ means surface absorption assumption, $r$ is reflectivity, $\mathrm{T}_{0}$ is initial and ambient temperature, $\mathrm{m}$ " is mass flow rate, $C_{g}$ is specific heat of gas, $\Delta H_{v}$ is enthalpy, $\mathrm{S}_{\mathrm{v}}$ is given by equation (5) .

Considering that the pyrolysis reaction is a first-order global reaction, the Arrhenius equation is applied and the mass equation is expressed as:

$$
\begin{gathered}
\frac{\partial \rho}{\partial t}=\rho S_{V} \\
S_{V}=-A \times \exp (-E / R T)
\end{gathered}
$$

In these equations, $\mathrm{A}$ is pre-exponential factor, $\mathrm{E}$ is activation energy, $\mathrm{R}$ is gas constant (8.31), $\mathrm{T}$ is the temperature of solid.

Predecessors generally assumed that the absorption coefficient was a constant in the numerical simulation $[6,7]$, but it was also considered that the absorption coefficient may be related to the wavelength or the material temperature $[8,9]$. Three constant absorption coefficients are selected and one of them is from previous literature [8]. Besides, I assume an absorption coefficient that which varies with the temperature is adopted, calculated by the equation as follow:

$$
\kappa=524.585+2.51601 \times 10^{7} \times e^{-0.03298 T}(6)
$$

This paper mainly discusses the accuracy of two different assumptions for the prediction of internal temperature of solid pyrolysis under windy conditions. In order to avoid the selection error of convective heat transfer coefficient, the experimentally measured temperature is used as the boundary condition. This means that the simulated boundary conditions are:

$$
\left\{\begin{array}{c}
\theta(\infty, t)=0 \\
T(0, t)=\text { measured temperature } \\
T(0.165, t)=\text { measured temperature }
\end{array}\right.
$$

The numerical simulation uses the experimentally measured temperature as the boundary layer to solve the temperature evolution of the middle two temperature layers with different governing equations. The simulation time, spatial and time steps are $200 \mathrm{~s}, 0.00025 \mathrm{~m}$ and $1 \mathrm{~s}$, respectively.

\section{Results and discussion}

Under the external heat flux, the material is gradually heated, and the internal temperature of the material is gradually increased. It is clear that there is a cooling 
effect on the material surface while the air flow sweeps across the surface of the material uniformly, but the influence on the internal temperature distribution of the material is relatively less studied.

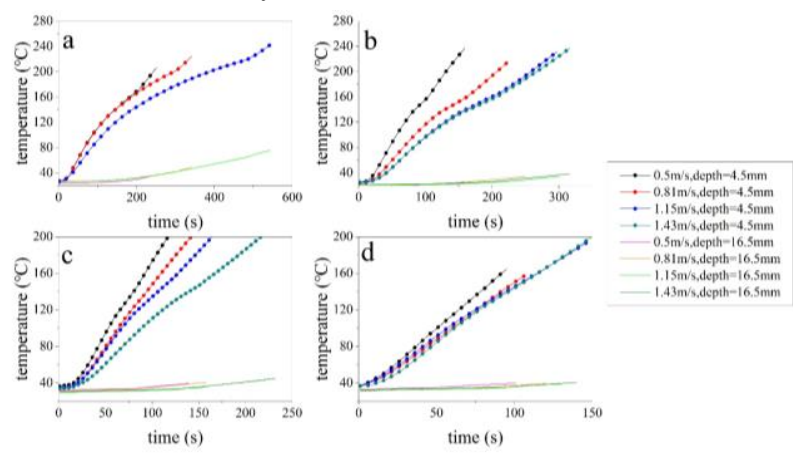

Figure 3. Internal temperature evolution under different external heat flux with variable airflow velocities: (a) 19.81 $\mathrm{kW} / \mathrm{m}^{2}$; (b) $25.2 \mathrm{~kW} / \mathrm{m}^{2}$; (c) $31.68 \mathrm{~kW} / \mathrm{m}^{2}$; (d) $35.47 \mathrm{~kW} / \mathrm{m}^{2}$.
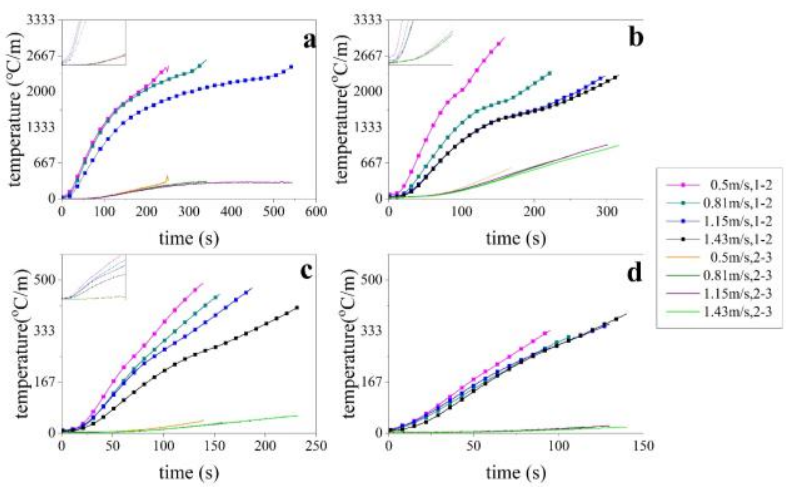

Figure 4. Internal temperature gradient evolution under different external heat flux with variable airflow velocities: (a) $19.81 \mathrm{~kW} / \mathrm{m}^{2}$; (b) $25.2 \mathrm{~kW} / \mathrm{m}^{2}$; (c) $31.68 \mathrm{~kW} / \mathrm{m}^{2}$; (d) 35.47 $\mathrm{kW} / \mathrm{m}^{2}$.

Figure 3 compares measured internal temperature for four series of representative experiments performed at external radiation of 19.81(a), 25.2(b), 31.68(c) and $35.47(\mathrm{~d}) \mathrm{kw} / \mathrm{m}^{2}$.

For the temperature at $4.5 \mathrm{~mm}$ from the surface of the material, as the heat flux increases, the effect of the air flow velocity increases first and then decreases. As for the temperature at $16.5 \mathrm{~mm}$ from the surface of the material, it is obvious that the flow velocity does not affect the temperature of this layer.

It can be suggested that there is a penetration thickness in the influence of the flow velocity, and this thickness is smaller than the heat penetration thickness (the temperature of the $16.5 \mathrm{~mm}$ layer in the figure is still rising, it implies that the thickness of the layer has not yet reached the thermal penetration thickness).

Figure 4 shows the temperature gradient of the different layers (1-2: $4.5-10.5 \mathrm{~mm}, 2-3: 10.5-16.5 \mathrm{~mm})$ under aforementioned external heat flux conditions. The small plots in a, b, and c plots have an abscissa of 0-150s and an ordinate of $0-500^{\circ} \mathrm{C} / \mathrm{m}$, which are used to compare with the $d$ plot. This figure reveals more clearly that airflow velocities has no effect on temperature gradient changes on layers 2-3 (10.5-16.5 mm). For the first layer $(4.5-10.5 \mathrm{~mm})$, the influence of airflow velocity increases first and then decreases with the increase of external heat flux, because there is a competition mechanism between external heat flux and airflow velocity.

Table 1. Thermal parameters of PMMA.

\begin{tabular}{|c|c|}
\hline Parameters & Values \\
\hline Density, $\rho(\mathrm{kg} / \mathrm{m} 3)$ & $1190[7]$ \\
\hline Specific heat, $\mathrm{C}_{\mathrm{P}}(\mathrm{J} /(\mathrm{gK}))$ & $1.42[7]$ \\
\hline Specific heat, $\mathrm{C}_{\mathrm{g}}(\mathrm{J} /(\mathrm{gK}))$ & $1.063[7]$ \\
\hline Thermal conductivity, $\mathrm{k}(\mathrm{J} /(\mathrm{smK}))$ & $-0.3+0.0015 \times \mathrm{T}$ \\
\hline Emission & $1[7]$ \\
\hline Pre-exponential factor, $\mathrm{A}_{\mathrm{s}}$ & $2.8 * 10^{9}$ \\
\hline Activation energy, $\mathrm{E}_{\mathrm{s}}(\mathrm{J} / \mathrm{mol})$ & $1.3 * 10^{5}$ \\
\hline Initial and ambient temperature, $\mathrm{T}_{0}(\mathrm{~K})$ & $300[7]$ \\
\hline In
\end{tabular}

In order to better reveal the internal temperature evolution law under windy conditions, numerical simulation using the parameters of Table 1 is completed. Surface absorption and depth absorption assumptions are compared in numerical simulations. For in-depth absorption assumption, three fixed and one temperaturedependent absorption coefficients were selected here, of which $\kappa=1870$ was from literature [8].
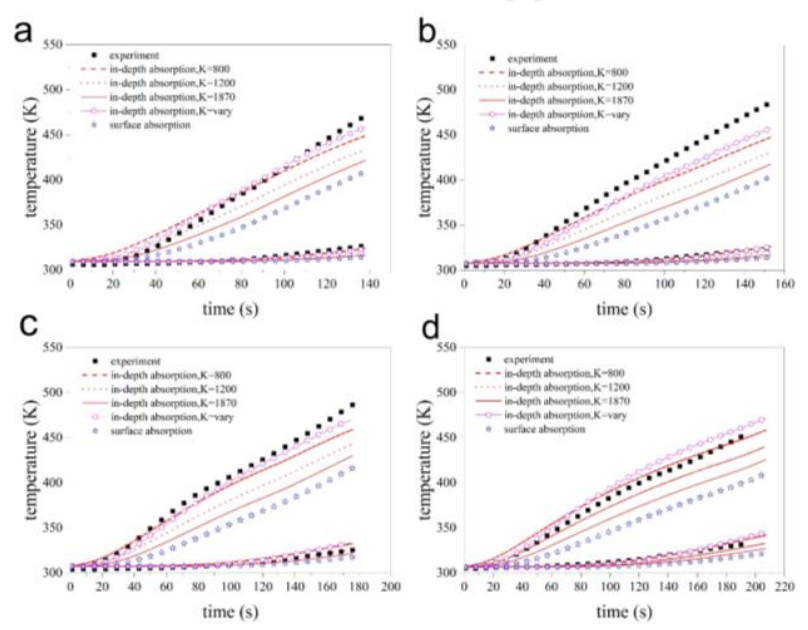

Figure 5. Comparison of internal temperature of PMMA at four flow velocity among experimental results and numerical simulation of in-depth absorption and surface absorption: (a) $v=$ $0.5 \mathrm{~m} / \mathrm{s} ;$ (b) $\mathrm{v}=0.81 \mathrm{~m} / \mathrm{s} ;$ (c) $\mathrm{v}=1.15 \mathrm{~m} / \mathrm{s} ;$ (d) $\mathrm{v}=1.43 \mathrm{~m} / \mathrm{s}$.

The experimental and numerical simulation results at the incident heat flux of $31.68 \mathrm{kw} / \mathrm{m}^{2}$ are shown in Figure 5. Although previous researchers implied that surface and in-depth absorption are the controlling mechanism for low $\left(<80 \mathrm{kw} / \mathrm{m}^{2}\right)$ and high heat fluxes, respectively [7], different result occurs under windy conditions. Under windy conditions, even if the external heat flux is less than $80 \mathrm{kw} / \mathrm{m}^{2}$, the in-depth absorption assumption is still 
applicable to explain the internal temperature evolution of the material.

Table 2. R square test results of temperature at $4.5 \mathrm{~mm}$.

\begin{tabular}{|c|c|c|c|c|}
\hline $\begin{array}{c}\text { In-depth } \\
\text { absorption } \\
\text { coefficients }\end{array}$ & $\mathbf{8 0 0}$ & $\mathbf{1 2 0 0}$ & $\mathbf{1 8 7 0}$ & Vary \\
\hline $0.5 \mathrm{~m} / \mathrm{s}$ & 0.964 & 0.896 & 0.759 & 0.989 \\
\hline $0.8 \mathrm{~m} / \mathrm{s}$ & 0.874 & 0.665 & 0.418 & 0.921 \\
\hline $1.15 \mathrm{~m} / \mathrm{s}$ & 0.950 & 0.785 & 0.559 & 0.983 \\
\hline $1.43 \mathrm{~m} / \mathrm{s}$ & 0.979 & 0.946 & 0.768 & 0.953 \\
\hline
\end{tabular}

Table 3. R square test results of temperature at $10.5 \mathrm{~mm}$.

\begin{tabular}{|c|c|c|c|c|}
\hline $\begin{array}{c}\text { In-depth } \\
\text { absorption } \\
\text { coefficients }\end{array}$ & $\mathbf{8 0 0}$ & $\mathbf{1 2 0 0}$ & $\mathbf{1 8 7 0}$ & Vary \\
\hline $0.5 \mathrm{~m} / \mathrm{s}$ & 0.863 & 0.633 & 0.429 & 0.821 \\
\hline $0.8 \mathrm{~m} / \mathrm{s}$ & 0.965 & 0.804 & 0.563 & 0.948 \\
\hline $1.15 \mathrm{~m} / \mathrm{s}$ & 0.661 & 0.932 & 0.840 & 0.713 \\
\hline $1.43 \mathrm{~m} / \mathrm{s}$ & 0.967 & 0.860 & 0.592 & 0.923 \\
\hline
\end{tabular}

Considering that the simulation results of different depth absorption coefficients are close, the goodness-offit is tested by R-square test, the results of that are shown in Tables 2 and 3. When the absorption coefficient is constant, the agreement between $\mathrm{K}=800$ and experimental results are relatively good, but the vary absorption coefficient fit better than it. Based on this, in order to use in windy environments previous pyrolysis models need to be improved.

\section{Conclusion}

1. Under constant external heat flux and windy conditions, the air flow velocity only affects the internal temperature of a certain thickness of the sample.

2. The effect of air flow velocity on internal temperature increases first and then decreases with the increase of external heat flux.

3. The in-depth absorption assumption is more suitable for explaining the internal temperature evolution of materials under windy conditions. And this work proposes a temperature-dependent in-depth absorption coefficient.

\section{Acknowledgments}

This work was supported by National Science Foundation of China (No.51636008), Key Research Program of Frontier Sciences, CAS (No.QYZDB-SSW-JSC029), the Fundamental Research Funds for the Central Universities (No. WK2320000040).

\section{References}

1. J. G. Quintiere, M. Harkleroad, D. Walton, Combustion Science and Technology 32,67-89 (1982)

2. L. Yang, Y. Wang, X. Zhou, J. Dai, Z. Deng, Journal of Fire Sciences 30, 211-223 (2012)

3. L.Z. Yang, X.J. Chen, X.D. Zhou, W.C. Fan, Combustion and Flame 133, 407-413 (2003)

4. K.C. Tsai, Journal of hazardous materials 172,763772 (2009)

5. J.R.Hallman, C.M.Sliepcevich, J.R.Welker, Journal of Fire Flammability 9,353-366 (1978)

6. C.A. Lautenberger,C, Fernandez-Pello, Fire Safety Journal 44, 819-839 (2009)

7. Gong Junhui, Li Yabo,Wang, Jinghong,Li, Jing,Chen, Yixuan, Jiang Juncheng, Wang Zhirong, Combustion and Flame 186 ,166-177 (2017)

8. G. Linteris , M. Zammarano , B. Wilthan , L. Hanssen , Fire Mater 36, 537-553 (2011)

9. M. J. Hurley, D. Gottuk, J.R. HallJr., K. Harada, E. Kuligowski, M. Puchovsky, J. Torero, J.M. WattsJr., C. Wieczorek, SFPE handbook of fire protection engineering, 115(2015) 